\title{
THE EXTENT OF THE ODONTOBLAST PROCESS IN RHESUS MONKEYS (MACACA MULATTA) AS OBSERVED BY SCANNING ELECTRON MICROSCOPY
}

\author{
K. W. Kelley, G. Bergenholtz and C. F. CoX \\ Laboratory of Oral Histology, The University of Michigan, 5213 School of Dentistry, \\ Ann Arbor, MI 48109, U.S.A.
}

\begin{abstract}
Summary-Monkeys were perfused with Karnovsky phosphate-buffered formalin-glutaraldehyde (PBF-GTA). Molars were removed and postfixed in PBF-GTA, demineralized in EDTA, freeze-fractured, and critical-point dried. Odontoblast processes were observed in tubules of the predentine, the pulpal inner third of dentine and in the peripheral dentine, but not in the middle third. Peripheral processes showed close adaptation to dentinal tubules with branches penetrating into canaliculi close to the dentine-enamel junction.
\end{abstract}

\section{INTRODUCTION}

The question of the extent of the odontoblast process into the dentinal tubule has been highly controversial. Investigators using histological staining methods recorded that these processes extend throughout the dentine and occasionally into the enamel (Tomes, 1856; Stack, 1896; Allen, 1932; Bevelander, 1941). Other investigators, using transmission electron microscopy (Holland, 1975, 1976; Thomas, 1979) and scanning electron microscopy (Brännström and Garberoglio, 1972; Tronstad, 1973), have reported that the odontoblast process traverses only in the inner pulpal third of dentine.

Our objective was to re-examine this area of controversy employing the scanning electron microscope with controlled perfusion techniques for fixation and critical-point drying.

\section{MATERIALS AND METHODS}

Two rhcsus monkeys (Macaca mulatta), approx. 5-7 yr old, were prepared for gravity-feed vascular perfusion (Cox, Heys and Heys, 1977). They were tranquilized with an intramuscular injection of $15 \mathrm{mg} / \mathrm{kg}$ body wt of ketamine hydrochloride; then deep anaesthesia was obtained with intravenous injection of 50-100 mg of sodium pentobarbitol which was trickled into the bloodstream until effective. Ten minutes prior to death, $1000-1500$ units of heparin were administered intravenously to prevent blood clotting during subsequent perfusion. The animals were perfused through the left ventricle with 0.9 per cent physiologic saline followed by Karnovsky phosphate-buffered formalin-glutaraldehyde (PBF-GTA) fixative (Cox et al., 1977).

Immediately after perfusion, two molars from each monkey were carefully removed from the jaws using a bone-cutting bur and bone cutters to eliminate buccal alveolar bone. During luxation of the teeth, care was taken not to put undue pressure on the tooth in order to prevent possible displacement of cell structures.
The apical half of the root was removed using a lowspeed handpiece equipped with a cross-cut carbide bur. The crowns were then gently agitated in PBF-GTA fixative for another $24 \mathrm{~h}$. The teeth were placed in a 50/50 mixture of pH 7.2, 0.5 M EDTA/ PBF-GTA solution for 14 days, replacing fresh solution daily. The incompletely demineralized teeth were frozen in liquid freon and fractured with sidecutting wire pliers to achieve a fracture along two longitudinal planes producing two or three samples from each tooth.

After freeze-fracturing, the samples were dehydrated in a graded ethanol series, 70, 80, 95 and 100 per cent, each at $1 \mathrm{~h}$ intervals. The samples were stored in 100 per cent benzene-dried ethanol overnight to remove any residual traces of water. Ethanol was removed by critical-point drying with $\mathrm{CO}_{2}$ in a Polaron E 3000 drier (Polaron Co., Watford, England). Samples were mounted on stubs for scanning electron microscopy (SEM), plasma-coated with approximately a $25 \mathrm{~nm}$ thick layer of gold, and observed with a JEOL JSM-U3 scanning electron microscope at $15 \mathrm{kV}$ (JEOL Inc., Peabody, Mass., U.S.A.).

\section{RESULTS}

Odontoblast cell profiles were consistently scen at the pulp-predentine border (Text Fig. 1, Plate Fig. 2) with the odontoblast processes extending approximately into the inner third of the respective tubule. At their pulpal ends, the diameter of each process typically measured $2-3 \mu \mathrm{m}$. Structures identical to odontoblast processes of juxta-pulpal dentine were also found at, or near, the dentine-enamel junction (DEJ) (Plate Fig. 3). These structures measured approx. $0.3-1.0 \mu \mathrm{m}$ in diameter and had the same surface features as those seen on juxta-pulpal processes (Plate Fig. 4). These peripheral structures showed many fine lateral branches of approx. $0.18 \mu \mathrm{m}$ in diameter. Higher magnification revealed that these branches were continuous with the main process and readily 


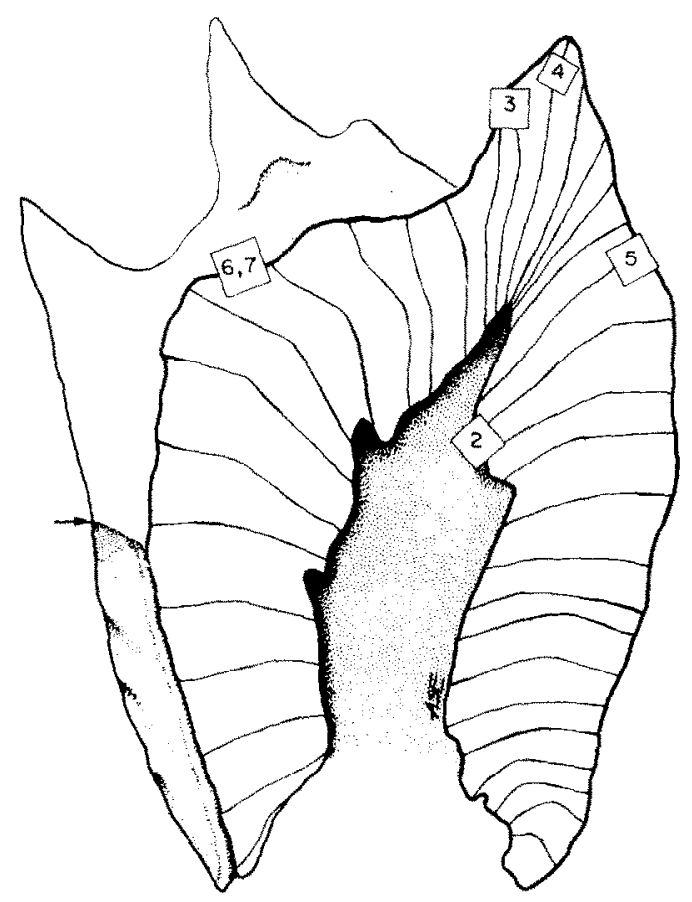

Fig. 1. Composite drawing of a fractured tooth specimen with the enamel removed. Approximate distance from the dental pulp to the dentine enamel junction is $1.7 \mathrm{~mm}$. The inset boxes correspond to areas from which photographs were taken in Plate 1. Arrow points to cemento-enamel junction.

distinguishable from dentine matrix and collagen fibres. In addition to the fine lateral branches, larger branches were seen where the main tubule joined large dentinal canaliculi (Plate Fig. 5). In all cases, the lateral branches were housed in smaller dentinal tubule canaliculi (Plate Figs 6 and 7). Odontoblast processes in peripheral dentine were observed in all 12 samples examined. All processes seemed to fill dentinal tubules incompletely both at the DEJ and at juxta-pulpal dentine, suggesting shrinkage.

In all samples, the tubules of the middle third of dentine, from the pulpal third to the peripheral third, were empty.

\section{DISCUSSION}

Odontoblast processes have been identified within coronal dentine by many investigators using electron microscopy (Isokawa et al., 1969; Brännström and Garberoglio, 1972; Tronstad, 1973; Holland, 1975, 1976; Thomas, 1979). All agree that the processes are tubular, contain cytoplasm bound by a limiting membrane, and are generally limited to the inner pulpal third of dentine. We found numerous odontoblast processes close to the puip arising from odontoblast cells within the pulp. Our finding that the processes could be followed only as far as the inner pulpal third of dentine, beyond which the tubules consistently appeared empty, confirms the observations of Brännström and Garberoglio (1972), Tronstad (1973), Holland (1975, 1976) and Thomas (1979). However, once approaching the dentine-enamel junction, structures were found whose surface morphology resem- bled odontoblast processes closer to the pulp in every way except size. These structures followed the branching course of the dentinal tubules. In addition, their smooth surface and tubular nature were identical to that of the odontoblast processes seen in juxta-pulpal dentine. We concluded that the structures observed in the peripheral parts of the dentinal tubules were extensions of odontoblast processes.

Not every tubule observed beyond the inner pulpal third of dentine contained an odontoblast process. This might be due to the freeze-fracturing procedure. When the tooth is frozen and then fractured, the odontoblast processes are scraped and may be torn from the tubules by the shearing action of the tooth halves during the fracturing process. Consequently, only those processes which are firmly embedded in dentine remain and those which are protected by overlying dentine or are held in position by many lateral branchings remain in place. This could explain why odontoblast processes were found primarily in the inner third of the dentine and at the dentineenamel junction, where the dentinal tubules were highly branched. It seems reasonable to assume that the odontoblast process is anchored at both ends, in the pulp by the odontoblast cell and at the dentineenamel junction by the branching into lateral canaliculi. Thus, the apparent lack of odontoblast processes in the tubules of mid-region dentine might be an artifact of mechanical preparation.

Our demonstration of odontoblast processes in peripheral dentine contradicts the findings of other investigators (Brännström and Garberoglio, 1972; Holland, 1975, 1976; Thomas, 1979). This may be explained by differences in techniques used: (1) critical-point drying versus freeze-drying (Brännström and Garberoglio 1972), (2) use of entire longitudinal sections of teeth rather than small sections taken at various intervals from dentine (Holland, 1975, 1976; Thomas, 1979), (3) use of perfusion fixative and demineralization in the presence of fixative.

Critical-point drying was used because it results in less artifactual destruction of cells and processes when compared to samples prepared using freeze-drying techniques. Odontoblast processes were not observed in peripheral dentine when samples were prepared by freeze drying.

Approximately 26 per cent linear shrinkage occurs using the critical-point drying technique (Boyde, 1978). This could also explain why the odontoblast processes did not completely fill the dentinal tubules in the specimens observed. Other investigators using transmission electron microscopic techniques (Holland, 1975, 1976; Thomas, 1979) have shown that the odontoblast process does indeed fill the dentinal tubule.

An advantage of the freeze-fracture method is that a large sample can be observed in the scanning microscope, rather than small ultra-thin sections required for transmission electron microscopy. Thus, a large area can be scanned at low magnification, and items of special interest examined more closely at higher magnifications.

The techniques of fixation and demineralization used here may also have aided in preserving the odontoblast processes at the dentine-enamel junction. The vascular perfusion technique gives superior pre- 
servation of tissues in the pulp (Cox et al., 1977). Due to the gravity-feed system, fixative reaches the most minute vascular beds. This process was facilitated by initial replacement of blood by physiologic saline and heparin to prevent small blood clots. By use of the combined demineralization/fixative solution, the preservation of structures at the dentine-enamel junction may occur by two processes: (1) the quick diffusion of the PBF-GTA fixative up the dentinal tubules from the pulp chamber (2) the percolation of the fixative through enamel towards the dentine-enamel junction, binding organic components, as the EDTA chelated and removed the inorganic components of enamel.

We made no attempt to quantify regional variations of the odontoblast process within dentine. We plan to address this subject in further depth.

Acknowledgements-We wish to thank Dr Keith S. Lester, Visiting Associate Professor from Sydney, Australia, for his expertise and advice throughout this project. This study was supported by Fund 333790 from The Laboratory of Oral Histology, School of Dentistry, The University of Michigan, Ann Arbor, MI., U.S.A.

\section{REFERENCES}

Allen C. 1932. The innervation of dentine and enamel. Aust. dent. J. 36, 39-51.

Bevelander G. 1941. The development and structure of the fiber system of dentin. Anat. Rec. 81, 79-97.

Boyde, A. 1978. Pros and cons of critical point drying and freeze drying for SEM. In: Scanning Electron Microscopy, an International of Advances in Biological Techniques and Applications of the Scanning Electron Microscope (Edited by Becker R. P. and Johari O.) Vol. 2. pp. 303-314. Scanning Electron Inc., AMF O'Hare. III. U.S.A.

Brännström M. and Garberoglio R. 1972. The dentinal tubules and the odontoblast process. A scanning electron microscope study. Acta odont. scand. 30, 291-311.

Cox C. F., Heys D. R. and Heys R. J. 1977. A gravity perfusion technique for lab animals. Lah. Anim. 6, 18-22.

Holland G. R. 1975. The extent of the odontoblast process in the cat. J. Anat. 120, 169-177.

Holland G. R. 1976. The extent of odontoblast process in the cat. J. Anat 121, 133-149.

Isokawa S., Toda Y., Kodama N. and Inoue Y. 1969-1970. Scanning electron microscopy of human odontoblasts and predentin. Nihon Univ. School dent. J. 11-12, 54-56.

Thomas H. F. 1979. The extent of the odontoblast process in human dentin. J. dent. Res. 58(D), 2207-2218.

Tomes J. 1856. On the presence of fibrils of soft tissue in soft tissue in the dentinal tubes. Phil Trans. R. Soc. Ser. B 146, 515-522.

Tronstad L. 1973. Ultrastructural observations on human coronal dentin. Scand. J. dent. Res. 81, 101-111.

Stack R. T. 1896. Touch bulbs in dentine. Dent. Cosmos 38, 875-876. 


\section{Plate 1.}

Fig. 2. Odontoblast cells (OD) closely adapted to the predentine indicate odontoblast processes $\left({ }^{*}\right)$ extending into tubules within the dentine (D). $\times 1360$

Fig. 3. Cuspal horn of dentine showing numerous dentinal tubules containing odontoblast processes in most of these tubules. $\times 850$

Fig. 4. Higher magnification of another area of the same cuspal horn of dentine as Fig. 3, though more toward the cusp tip. Two odontoblast processes approx. $0.8 \mu \mathrm{m}$ in diameter in subjacent dentinal tubules, with numerous fine lateral branchings approx. $0.18 \mu \mathrm{m}$ are observed. $\times 2550$

Fig. 5. Two dentinal tubules branch $\left({ }^{*}\right)$ as they approach the DEJ. Canaliculi (arrows) are also evident. $\times 4250$

Fig. 6. Odontoblast process (arrow) in a dentinal tubule as it branches close to the DEJ. $\times 2550$

Fig. 7. Higher magnification of Fig. 6 , showing the main odontoblast process and a large lateral branch (arrow) with several smaller branches at its distal end $\left(^{*}\right) . \times 8500$ 

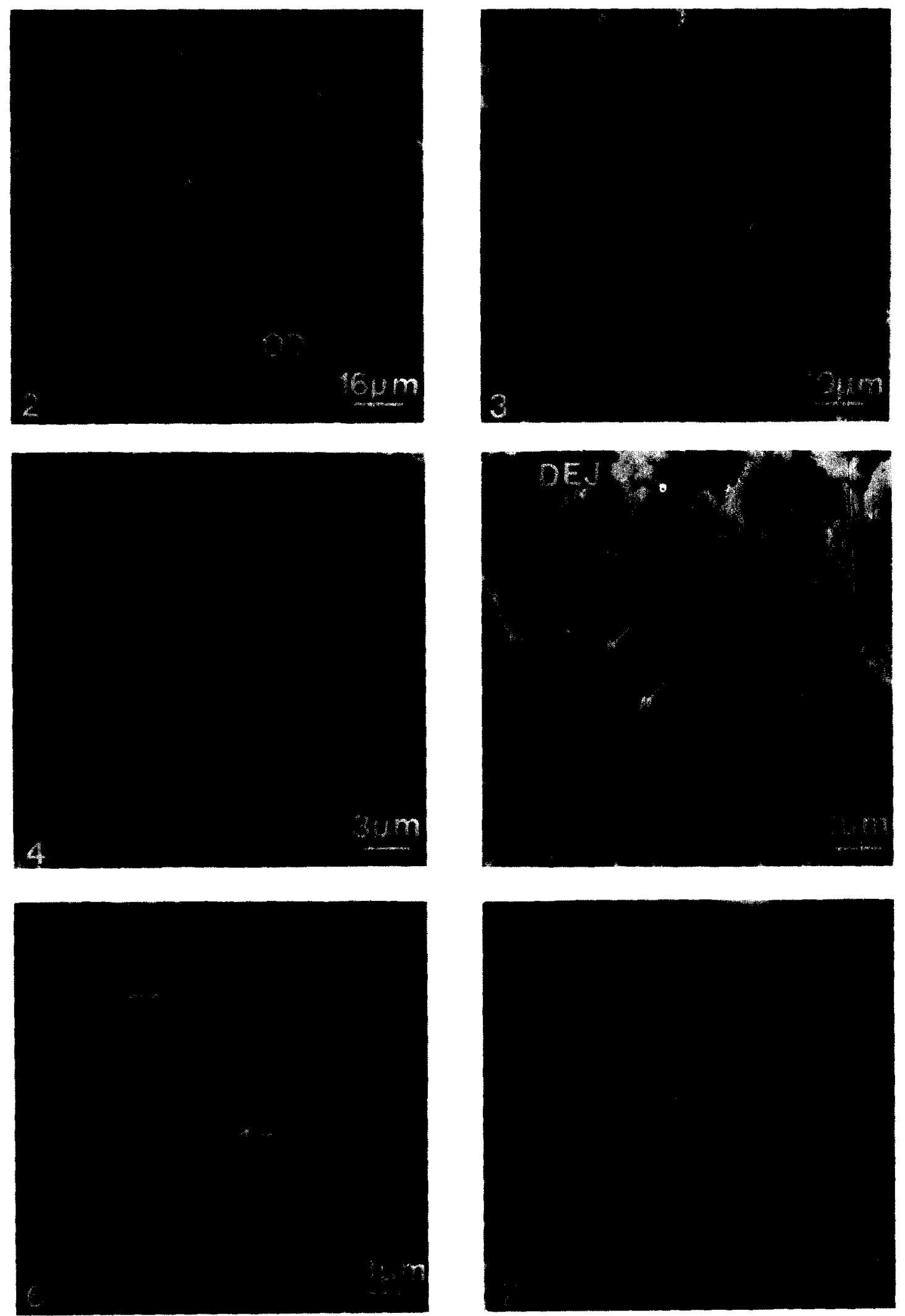

Plate 1. 